\title{
Maternal proviral load and vertical transmission of Human T cell Lymphotropic Virus type 1 in Guinea-Bissau
}

\author{
Carla van Tienen ${ }^{1,2^{*}}$, Samuel J McConkey ${ }^{1}$, Thushan I de Silva ${ }^{1,3}$, Matthew Cotten ${ }^{1}$, Steve Kaye ${ }^{1}$, Ramu Sarge-Njie ${ }^{1}$, \\ Carlos da Costa ${ }^{1,4}$, Nato Gonçalves ${ }^{1,4}$, Julia Parker ${ }^{1}$, Tim Vincent ${ }^{1}$, Assan Jaye ${ }^{1}$, Peter Aaby ${ }^{5}$, Hilton Whittle ${ }^{1}$, \\ Maarten Schim van der Loeff ${ }^{1,6}$
}

From 15th International Conference on Human Retroviruses: HTLV and Related Viruses Leuven and Gembloux, Belgium. 5-8 June 2011

\section{Background}

The relative importance of routes of transmission of Human T cell Lymphotropic Virus type 1 (HTLV-1) in Guinea-Bissau is largely unknown; vertical transmission is thought to be important, but there are very few existing data. We aimed to examine factors associated with transmission in mothers and children in Guinea-Bissau, where HTLV-1 is endemic (prevalence of $5 \%$ ).

\section{Methods}

A cross-sectional survey was performed among mothers and their children (aged $<15$ years) in a rural community in Guinea-Bissau. A questionnaire to identify risk factors for infection and a blood sample were obtained. HTLV-1 proviral load in peripheral blood was determined and PCR was performed to compare Long Terminal Repeat (LTR) sequences in mother-child pairs.

\section{Results}

Fourteen out of 55 children (25\%) of 31 HTLV-1 infected mothers were infected versus none of 70 children of 30 uninfected mothers. The only factor significantly associated with HTLV-1 infection in the child was the proviral load of the mother; the risk of infection increased significantly with the $\log 10$ proviral load in the mother's peripheral blood (OR 5.5, 95\% CI 2.1-14.6, per quartile), adjusted for weaning age and maternal income. HTLV-1 sequences of the LTR region obtained from mother-child pairs were identical within pairs but differed between the pairs.

\section{Conclusions}

Vertical transmission plays an important role in HTLV1 transmission in this community in Guinea-Bissau. The risk of transmission increases with the mother's proviral load in the peripheral blood. Identical sequences in mother-child pairs give additional support to the maternal source of the children's infection.

\section{Author details}

${ }^{1}$ Viral diseases program, Medical Research Council, Fajara, Gambia. ${ }^{2}$ Department of Medical Microbiology and Infectious Diseases, Erasmus Medical Centre, Rotterdam, Netherlands. ${ }^{3}$ Centre for Medical Molecular Virology, Division of Infection and Immunity, University College London, London, UK. ${ }^{4}$ Projecto de Saúde de Bandim, Bissau. Guinea-Bissau. ${ }^{5}$ Projecto de Saúde de Bandim/Indepth Network, Bissau, Guinea-Bissau. ${ }^{6}$ Municipal Health Services, Amsterdam, Netherlands.

Published: 6 June 2011

doi:10.1186/1742-4690-8-S1-A72

Cite this article as: van Tienen et al: Maternal proviral load and vertical transmission of Human T cell Lymphotropic Virus type 1 in GuineaBissau. Retrovirology 2011 8(Suppl 1):A72.

* Correspondence: carlavantienen@gmail.com

${ }^{1}$ Viral diseases program, Medical Research Council, Fajara, Gambia

Full list of author information is available at the end of the article 